\title{
Micropropagação e germinação de sementes in vitro de atroveran
}

\author{
Lucila Elizabeth Fragoso Monfort ${ }^{1}$, José Eduardo Brasil Pereira Pinto ${ }^{* 2}$, Suzan Kelly Vilela Bertolucci ${ }^{3}$, \\ Zélia Terezinha Teixeira Rossi", Andreísa Fabri Lima ${ }^{5}$, Sâmia Torres Silva ${ }^{6}$, Giselly Mota da Silva ${ }^{6}$
}

http://dx.doi.org/10.1590/0034-737X201562020012

\section{RESUMO}

Atroveran (Ocimum selloi Benth. - Lamiaceae) é uma espécie medicinal, usada para distúrbios digestivos e tratamento de inflamações. O objetivo deste trabalho foi avaliar o estabelecimento de segmentos nodais, germinação e crescimento, in vitro, de plântulas de atroveran, em diferentes concentrações de sacarose do meio MS e a aclimatização de plântulas em diferentes substratos. Para o estabelecimento e crescimento, utilizaram-se três concentrações do meio de cultura (MS, 1/2MS e 1/4MS) e duas concentrações de sacarose (15 g/L, $30 \mathrm{~g} / \mathrm{L}$ e o controle). Para a germinação, as variações do meio de cultura foram: MS, 1/2MS, 1/4MS e 0MS (controle) e duas concentrações de sacarose (15 g/L, $30 \mathrm{~g} / \mathrm{L}$ e o controle). Para a aclimatização, avaliaram-se os substratos: areia fina lavada, substrato comercial, solo e solo+esterco bovino (2:1). O uso de sacarose foi essencial para o estabelecimento e crescimento dos segmentos nodais de atroveran. Recomendam-se, assim, $15 \mathrm{~g} / \mathrm{L}$ de açúcar. O 1/2MS é o mais indicado para o estabelecimento dos explantes e, o 1/4MS, para o crescimento de segmentos nodais desta espécie. Maior percentagem de germinação e maior índice de velocidade de germinação foram observados na ausência da sacarose. Para o crescimento até 30 dias, recomenda-se o uso do meio 1/4MS sem sacarose e, para manutenção das plântulas, in vitro, o meio 1/4MS suplementado com $15 \mathrm{~g} / \mathrm{L}$ de sacarose. Para a aclimatização de atroveran, o substrato comercial proporcionou maior crescimento das plântulas.

Palavras-chave: Ocimum selloi, Lamiaceae, MS, sacarose, aclimatização.

\section{ABSTRACT}

\section{Micropropagation and in vitro seed germination of atroveran}

Atroveran (Ocimum selloi Benth. - Lamiaceae) is medicinal plant used for digestive disturbs and inflammation. The objectives of this study were to establish nodal segments, seed germination and in vitro plantlet growth on sucrose and different basal salt concentrations, as well as plantlet acclimatization in different substrates. For establishment and growth, three different basal salt formulations (MS, $1 / 2 \mathrm{MS}$ and $1 / 4 \mathrm{MS}$ ) and two concentration of sucrose $(15 \mathrm{~g} / \mathrm{L}, 30 \mathrm{~g} / \mathrm{L}$ and control) were used. For seed germination, MS, 1/2MS, 1/4MS and 0MS (control) and two sucrose $\left(15 \mathrm{~g} / \mathrm{L}, 30 \mathrm{~g} / \mathrm{L}\right.$ and control) were used. For acclimatization, the substrates sand, Plantmax ${ }^{\circledR}$, soil and soil + cattle manure $(2: 1)$ were used. The results indicated $15 \mathrm{~g} / \mathrm{L}$ of sucrose to establish the explant and nodal segment growth. The $1 / 2 \mathrm{MS}$ basal salt formulation was better to establish the explant and $1 / 4 \mathrm{MS}$ to nodal segment growth of $O$. selloi. The results indicated higher seed germination percentage and germination speed index on medium without

'Universidade Federal de Lavras, Departamento de Agricultura, Laboratório de Cultura de Tecidos e Plantas Medicinais, Lavras, Minas Gerais, Brasil. lucilaagro@yahoo.com.br ${ }^{2}$ Universidade Federal de Lavras, Departamento de Agricultura, Laboratório de Cultura de Tecidos e Plantas Medicinais, Lavras, Minas Gerais, Brasil. jeduardo@dag.ufla.br ${ }^{3}$ Universidade Federal de Lavras, Departamento de Agricultura, Laboratório de Cultura de Tecidos e Plantas Medicinais, Lavras, Minas Gerais, Brasil. suzan@dag.ufla.br ${ }^{4}$ Universidade Federal de Lavras, Departamento de Agricultura, Laboratório de Cultura de Tecidos e Plantas Medicinais, Lavras, Minas Gerais, Brasil. zeliattrossi@ hotmail.com ${ }^{5}$ Universidade Federal de Lavras, Departamento de Agricultura, Laboratório de Cultura de Tecidos e Plantas Medicinais, Lavras, Minas Gerais, Brasil. andreisafabrilima@ yahoo.com.br ${ }^{6}$ Universidade Federal de Lavras, Departamento de Agricultura, Laboratório de Cultura de Tecidos e Plantas Medicinais, Lavras, Minas Gerais, Brasil. samiatorres.agronomia @ gmail.com; gisellymota@yahoo.com.br

*Autor para correspondência: jeduardo@dag.ufla.br
} 
sucrose. For growth up to 30 days better results were observed on 1/4MS without sucrose and for plantlet to maintain growth of $O$. selloi in vitro the better results indicated $1 / 4 \mathrm{MS}$ supplemented with $15 \mathrm{~g} / \mathrm{L}$ of sucrose. Plantlet acclimatization of $O$. selloi in the substratum Plantmax ${ }^{\circledR}$ gave better growth.

Key words: Ocimum selloi, Lamiaceae, MS, sucrose, acclimatization.

\section{INTRODUÇÃO}

O atroveran (Ocimum selloi Benth.), pertencente à família Lamiaceae, é uma espécie anual herbácea, nativa das regiões sudeste e sul do Brasil, também conhecida como elixir paregórico, anis e alfavaquinha. Em estudos etnobotânicos, constatou-se que a planta é utilizada, por via oral, em distúrbios digestivos e para o tratamento de inflamações, como gastrite e bronquite (Vieira \& Simon, 2000).

Graças ao crescimento do uso de plantas medicinais para estudo fitoquímicos da utilização de matéria prima para produção de fitoterápicos, tornou-se importante o desenvolvimento de um protocolo para produção de mudas de qualidade de $O$. selloi. A qualidade e a uniformidade da matéria-prima são muito importantes e devem ser exigidas na produção de um medicamento. Estudos da propagação in vitro de plantas medicinais vêm sendo realizados com o objetivo de obter plantas homogêneas, com qualidade fitossanitária, identidade genética, caracterização bioquímica e alta produção de metabólitos secundários (Murch et al., 2004).

Durante o cultivo in vitro, as soluções de sais e açúcares que compõem os meios de cultura não exercem efeito puramente nutritivo, mas, também, influenciam o crescimento celular e a morfogênese, por meio de propriedades osmóticas (George et al., 2008). Diversas formulações de meios básicos têm sido utilizadas no cultivo in vitro. Não há uma formulação padrão, mas o meio MS (Murashige \& Skoog, 1962), com suas modificações e diluições, tem sido utilizado com sucesso para diversas espécies.

Condições ambientais apropriadas para o processo de germinação podem ser fornecidas em laboratórios, como o controle de luz, temperatura e umidade. Ferreira e Rosa (2009) testando a influência de temperatura e luz, em condições laboratoriais, em sementes de $O$. selloi, verificaram que as sementes apresentam comportamento fotoblástico positivo, sendo que os regimes com temperaturas de 20 ou $25^{\circ} \mathrm{C}$, na presença de luz, foram os mais favoráveis, embora, tanto na ausência de luz como na alternância de temperaturas, tenham mostrado eficiência para a germinação desta espécie.

$\mathrm{O}$ processo de germinação de sementes in vitro, visando à produção de mudas, tem sido utilizado em outras espécies. Bevilacqua et al. (2011) germinaram sementes de calêndula, em um quarto da força do meio MS, suplementado com $15 \mathrm{~g} / \mathrm{L}$ de sacarose. Germinação in vitro de sementes de alcachofra foram viáveis, no meio MS completo e com o teor de sais reduzido à metade (Moraes et al., 2010). O uso da germinação in vitro de sementes de Vanda coerulea tem auxiliado na propagação da espécie, ameaçada de extinção (Roy et al., 2011).

Uma etapa crítica da micropropagação é a aclimatização, por causa da dificuldade de transferir, com sucesso, plantas da condição in vitro para a de casa de vegetação e, posteriormente, para a de campo. Durante a micropropagação, as plantas são mantidas em ambiente totalmente controlado. A transferência para condições naturais, por ser uma mudança brusca, deve ocorrer paulatinamente, pois as plantas não estão adaptadas ao novo ambiente. Outro fator importante na aclimatização de mudas é o substrato (Calvete et al., 2000), devendo apresentar boa coesão entre as partículas e adequada aderência junto às raízes.

Silva et al. (2007) observaram que plantas de Aloe vera, aclimatizadas em substrato comercial, durante 60 dias, em casa de vegetação $\left(25 \pm 2{ }^{\circ} \mathrm{C}, 80 \%\right.$ de UR do ar e $40 \%$ de redução da radiação solar), apresentaram $95 \%$ das plantas prontas para serem transplantadas em definitivo para o campo de produção.

Este trabalho objetivou avaliar o estabelecimento de explantes, a germinação e o crescimento, in vitro, de plântulas de atroveran, em diferentes concentrações de sacarose e do meio MS e o efeito de diferentes substratos na aclimatização de suas plântulas.

\section{MATERIAL E MÉTODOS}

\section{Condições gerais do cultivo dos experimentos}

A exsicata da espécie foi depositada no herbário da ESAL, localizado no Departamento de Biologia da Universidade Federal de Lavras (UFLA), em Lavras, MG, sob o registro $\mathrm{n}^{\circ} 7474$. O meio de cultura foi solidificado com $6 \mathrm{~g} / \mathrm{L}$ de ágar, o $\mathrm{pH}$ ajustado para $5,7 \pm 0,1$, antes da autoclavagem a $120^{\circ} \mathrm{C}$ e $1 \mathrm{~atm}$, por 20 minutos. Os tubos de ensaio foram mantidos em sala de crescimento, com fotoperíodo de 16 horas de luz por 8 horas de escuro, sob intensidade luminosa de $25 \mu \mathrm{mol} \mathrm{m}{ }^{2} \mathrm{~s}^{-1}$, à temperatura de $26 \pm 0,1^{\circ} \mathrm{C}$. 
Os dados obtidos foram submetidos à ANOVA, pelo teste $\mathrm{F}(\mathrm{p}<0,05)$, sendo as médias dos tratamentos agrupadas pelo teste de Scott-Knott $(\mathrm{p}<0,05)$, utilizando-se o software Sisvar ${ }^{\circledR}$, versão 5.0 (Ferreira, 2007).

\section{Experimento 1: Estabelecimento e crescimento in vitro de segmentos nodais de $\mathbf{O}$. selloi}

a) Estabelecimento do explante in vitro de $\mathrm{O}$. selloi

Plantas adultas de $O$. selloi, cultivadas em canteiros, utilizando-se esterco de curral $\left(6 \mathrm{Kg} \mathrm{m}^{-2}\right)$ e com 90 dias de cultivo, provenientes do Horto Medicinal da UFLA, serviram como doadoras de segmentos nodais primários. Após coleta, as plantas foram levadas ao laboratório e os segmentos foram lavados em água corrente (30 minutos) e imersos em solução de hipoclorito de sódio comercial a 50\% (15 minutos). Em seguida, foram lavados cinco vezes em água destilada autoclavada. Os segmentos (1,0 $\mathrm{cm}$ ) foram inoculados em tubos de ensaio com $10 \mathrm{~mL}$ do meio MS, num fatorial ( $3 \times 3$ ), sendo três as variações do MS (MS, 1/2MS e 1/4MS) e três concentrações de sacarose (15 g/L, $30 \mathrm{~g} / \mathrm{L}$ e o controle - $0 \mathrm{~g} / \mathrm{L})$.

Após 30 dias, avaliaram-se o número, o comprimento $(\mathrm{cm})$ e as massas da matéria seca, $(\mathrm{mg})$, das brotações e das raízes. Foi utilizado o delineamento inteiramente casualizado, com cinco repetições, sendo dez tubos por repetição e um segmento por tubo.

\section{b) Crescimento do segmento nodal in vitro de $\mathbf{O}$. selloi}

Plântulas estabelecidas in vitro serviram como doadoras de segmentos nodais inoculados em tubos de ensaio com $10 \mathrm{~mL}$ de meio de cultura MS. O experimento foi montado em fatorial $3 \times 3$, sendo três as variações do MS (MS, 1/2MS e 1/4MS) e três concentrações de sacarose (15 g/L, $30 \mathrm{~g} / \mathrm{L}$ e o controle - $0 \mathrm{~g} / \mathrm{L})$.

Após 30 dias, avaliaram-se o número, o comprimento $(\mathrm{cm})$, as massas da matéria seca $(\mathrm{mg})$ das brotações e das raízes. Foi utilizado o delineamento inteiramente casualizado, com cinco repetições, sendo dez tubos por repetição e um segmento por tubo.

\section{Experimento 2: Efeito da concentração do meio de cultura na germinação de sementes $e$ crescimento in vitro da plântula}

\section{a) Assepsia das sementes}

As sementes foram coletadas de plantas adultas de O. selloi, lavadas com água corrente e sabão neutro. Depois, imersas em solução de hipoclorito de sódio comercial (70\%), por 15 minutos, sob agitação, e lavadas cinco vezes em água destilada e autoclavada.

\section{b) Condução do ensaio}

As sementes foram inoculadas em diferentes concentrações do meio de cultura (MS, 1/2MS, 1/4MS e o controle - água) e três concentrações de sacarose (15 g/ $\mathrm{L}, 30 \mathrm{~g} / \mathrm{L}$ e o controle - $0 \mathrm{~g} / \mathrm{L})$. O experimento foi montado em fatorial 4 × 3 totalizando 12 tratamentos, com cinco repetições, sendo cinco tubos por repetição e uma semente por tubo.

\section{c) Avaliação}

As avaliações iniciaram-se após três dias da inoculação das sementes, quando ocorreu a protusão da radícula. Para cálculo do Índice de Velocidade de Germinação (IVG) (Maguire, 1962), foi realizada a contagem, durante sete dias seguidos, do número de sementes em que houve a protusão da radícula em cada tratamento, sendo, nesse mesmo período, avaliada a percentagem de germinação, com base no número de plantas normais (Brasil, 1992). Após 30 dias, avaliou-se o comprimento da parte aérea das plântulas germinadas, as produções de matéria fresca e seca da parte aérea $(\mathrm{mg})$, o número de raízes, as produções de matéria fresca e seca de raízes (mg).

\section{Experimento 3: Efeito do tipo de substrato na aclimatização da plântula}

\section{a) Condução do ensaio}

Plântulas micropropagadas de $O$. selloi, oriundas de subcultivo em meio 1/2MS suplementado de $15 \mathrm{~g} / \mathrm{L}$ de sacarose, foram utilizadas. As raízes foram lavadas com água corrente e transplantadas para bandejas plásticas de $36 \mathrm{~cm}$ x $27 \mathrm{~cm}$, com 24 células cada. A aclimatização foi realizada em casa de vegetação, com nebulização intermitente, temperatura $\pm 26{ }^{\circ} \mathrm{C}$ e sombreamento de $70 \%$. Os substratos avaliados foram: areia lavada, substrato comercial, solo (Latossolo Vermelho-Escuro) e solo + esterco bovino, na proporção de 2:1, totalizando quatro tratamentos. Foi utilizado o delineamento inteiramente casualizado, com cinco repetições e quatro plântulas por repetição.

\section{b) Avaliação}

Aos 45 dias, avaliaram-se a percentagem de sobrevivência, o comprimento da planta $(\mathrm{cm})$, o número de entrenós, a as produções de matéria seca da parte aérea $(\mathrm{mg})$, o comprimento da maior raiz $(\mathrm{cm})$ e a as produções de matéria seca do sistema radicular (mg).

\section{RESULTADOS E DISCUSSÃO}

\section{Experimento 1: Estabelecimento e crescimento in vitro de segmentos nodais de $\mathbf{O}$. selloi \\ a) Estabelecimento do explante in vitro de $\mathbf{O}$. selloi}

A percentagem de contaminação in vitro é influenciada pelo sistema de cultivo da espécie em estudo e pela época do ano. A contaminação do explante in vitro 
é um problema sério, no estabelecimento de uma cultura primária, e torna-se um entrave para a multiplicação. No estabelecimento in vitro dos segmentos nodais de O. selloi, apenas 9,87\% dos tubos apresentaram contaminação por fungos. Tratando-se de material proveniente do campo, esse resultado indica boa eficiência do processo de assepsia.

No segmento nodal, foi observada a indução de raízes no explante primário. Esta formação de raízes foi influenciada conjuntamente pelas concentrações do meio MS e de sacarose, tanto para o comprimento como para a produção de matéria seca (Tabela 1). A diferença da concentração de sais no meio básico é um fator importante na indução de raízes. Normalmente, alta concentração inibe e, baixa concentração induz o enraizamento. No segmento nodal de $O$. selloi em meio $1 / 2 \mathrm{MS}$, a suplementação de $15 \mathrm{~g} / \mathrm{L}$ de sacarose, induziu maior comprimento da raiz. Quando houve um suplemento de $30 \mathrm{~g} / \mathrm{L}$ de sacarose, o meio com um quarto da força do MS (1/4MS) induziu maior comprimento. Com o uso do meio completo do MS, o comprimento da raiz mostrou-se menor. Isso sugere que altas concentrações do meio básico do MS podem ser tóxicas para o crescimento da raiz ou um efeito osmótico. O maior comprimento de raiz, observado no meio de cultura com baixo nível de sais (1/4MS) e $30 \mathrm{~g} / \mathrm{L}$ de sacarose, pode ser devido, principalmente, à diminuição do nível de nitrogênio. $\mathrm{O}$ meio MS contém $60 \mathrm{mM}$ de nitrogênio, o meio 1/2MS $30 \mathrm{mM}$ e 1/4MS $15 \mathrm{mM}$. O meio básico enriquecido com nitrogênio é fundamental para a diferenciação da parte aérea. O meio MS é considerado um meio de cultura com altas concentrações de sais. Neste estudo, constatou-se que a diminuição da concentração desses sais favoreceu o crescimento das raízes. Frequentemente, o crescimento de raiz é inibido por $\mathrm{NH}_{4}^{+}$e promovido por $\mathrm{NO}_{3}$. Uma maior relação de nitrato/amônio, em meio com menor concentração de nitrogênio, pode ter ocorrido para auxiliar no enraizamento.
A utilização de sacarose na composição do meio de cultura foi fundamental para o enraizamento in vitro de segmento nodal de $O$. selloi. Isso pode ter ocorrido pelo fato de o gasto energético da plântula na produção de raízes serem elevado. A concentração de sais e sacarose também influenciou conjuntamente a produção de matéria seca das raízes. Os meios básicos do MS, com meia e um quarto da força dos sais, resultaram em maior acúmulo de matéria seca. Trabalhos realizados por Sun et al. (2010) com Ilex glabra mostraram que a concentração do meio básico é fundamental para o enraizamento, mas as diferentes respostas são, principalmente, devidas ao genótipo.

Não houve diferença estatisticamente significativa das diluições do meio MS sobre o número, comprimento e matéria seca das brotações. Para o número de raízes, o meio MS completo apresentou efeito negativo no desenvolvimento do tecido radicular (Tabela 2). Pessoa et al. (2004), trabalhando com samambaia (Nephrolepis exaltata), corroboram estes resultados e, em amoreirapreta (Rubus sp.), o número de brotos foi estimulado pelo aumento da concentração de sais do MS (Villa et al., 2005).

A ausência de sacarose proporcionou efeito negativo sobre o número, comprimento, matéria seca da brotação e número de raízes. Para número de brotações e de raízes, as concentrações de $15 \mathrm{~g} / \mathrm{L}$ e $30 \mathrm{~g} / \mathrm{L}$ de sacarose resultaram maior ganho, não apresentando diferença entre si. Para comprimento e matéria seca de brotação, o melhor tratamento foi o que utilizou $15 \mathrm{~g} / \mathrm{L}$ de sacarose (Tabela 2).

\section{b) Crescimento segmento nodal in vitro de $\mathbf{O}$. selloi}

Após o estabelecimento do segmento nodal primário, as plântulas desenvolvidas foram repicadas para que fosse estudado o seu crescimento in vitro. As concentrações de sais e de sacarose influenciaram conjunta-

Tabela 1. Valores médios do comprimento de raízes (cm) e do acúmulo de matéria seca de raiz (mg) de Ocimum selloi cultivado sob diferentes concentrações de meio de cultura MS e de sacarose, aos 30 dias

\begin{tabular}{|c|c|c|c|}
\hline \multirow{2}{*}{ Meio de cultura } & \multicolumn{3}{|c|}{ Sacarose $(g / L)$} \\
\hline & $\mathbf{0}$ & 15 & 30 \\
\hline & \multicolumn{3}{|c|}{ Comprimento de raízes $(\mathrm{cm})$} \\
\hline $1 / 4 \mathrm{MS}$ & $0,10 \mathrm{bA}$ & 1,02 a B & 1,25 a A \\
\hline $1 / 2 \mathrm{MS}$ & $0,04 \mathrm{c} \mathrm{A}$ & 1,66 a A & $0,85 \mathrm{~b} \mathrm{~B}$ \\
\hline \multirow[t]{2}{*}{ MS } & $0,00 \mathrm{~b} \mathrm{~B}$ & 0,24 a C & 0,48 a B \\
\hline & \multicolumn{3}{|c|}{ Matéria seca de raiz $(\mathrm{mg})$} \\
\hline $1 / 4 \mathrm{MS}$ & $0,020 \mathrm{bA}$ & 0,720 a A & 0,420 a A \\
\hline $1 / 2 \mathrm{MS}$ & $0,004 \mathrm{~b} \mathrm{~A}$ & $1,100 \mathrm{a} A$ & $0,320 \mathrm{~b} \mathrm{~A}$ \\
\hline MS & $0,000 \mathrm{~b} \mathrm{~B}$ & 0,038 a B & 0,192 a A \\
\hline
\end{tabular}

Médias seguidas da mesma letra, minúsculas na linha e maiúsculas na coluna, pertencem ao mesmo grupo de acordo com o teste Scott-Knott, a 5\% de probabilidade.

Rev. Ceres, Viçosa, v. 62, n.2, p. 215-223, mar-abr, 2015 
mente o comprimento e acúmulo de matéria secas das brotações e das raízes e o número de raízes.

Em relação ao comprimento da brotação, na concentração de $15 \mathrm{~g} / \mathrm{L}$ de sacarose, o meio 1/4MS mostrou ser o mais indicado. Já na concentração de $30 \mathrm{~g} / \mathrm{L}$ de sacarose, o melhor tratamento foi o MS. Para todos os meios utilizados, a sacarose, na concentração de $15 \mathrm{~g} / \mathrm{L}$, proporcionou efeito positivo em todos os parâmetros avaliados (Tabela 3 ).

Na ausência de sacarose não houve efeito do meio MS sobre o comprimento e massa das brotações. Esse resultado demonstrou a importância da sacarose no meio básico, para fornecer energia ao crescimento da brotação. Na concentração de $15 \mathrm{~g} / \mathrm{L}$ de sacarose, os meios $1 / 2 \mathrm{MS}$ e MS resultaram em aumento do peso em relação a $1 / 4 \mathrm{MS}$, não se diferenciando entre si. A matéria seca, produzida na concentração de $30 \mathrm{~g} / \mathrm{L}$ de sacarose, no MS completo, foi superior às produzidas nas diluições do MS. Com os meios $1 / 4 \mathrm{MS}$ e $1 / 2 \mathrm{MS}$, a sacarose na concentração de $15 \mathrm{~g} / \mathrm{L}$ influenciou aumentou o peso das brotações. Com o meio MS, as concentrações de $15 \mathrm{~g} / \mathrm{L}$ e $30 \mathrm{~g} / \mathrm{L}$ de sacarose resultaram em massas de brotações similares. A ausência de sacarose deve ter proporcionado menor fonte de carbono e, consequentemente, menor acúmulo de matéria seca. A média da matéria seca, nas diferentes concentrações de sais do MS, suplementado com $15 \mathrm{~g} / \mathrm{L}$ de sacarose, foi 61 vezes superior à do meio sem sacarose, e 50 vezes maior, quando o meio foi suplementado com $30 \mathrm{~g} / \mathrm{L}$ de sacarose. A sacarose foi essencial ao crescimento das gemas axilares no segmento nodal de atroveran. Sem a sacarose, não há o fornecimento adequado de esqueleto de carbono para a biossíntese de proteína e, consequentemente, para o crescimento do explante.

A concentração de $15 \mathrm{~g} / \mathrm{L}$ de sacarose favoreceu o desenvolvimento da plântula cultivada in vitro, indicando que a presença desse carboidrato no meio de cultivo foi essencial para o desenvolvimento da plântula micropropagada. Maiores concentrações de sacarose aumentam o efeito osmótico do meio de cultura, podendo prejudicar o desenvolvimento da plântula cultivada in vitro. Fráguas et al. (2003), trabalhando com Cattleya labiata e Laelia itambana, obtiveram resultados semelhantes.

Na Tabela 3, são apresentados os valores médios de número, comprimento e matéria seca de raízes. Não houve formação de raiz na ausência de sacarose. A análise indica que, tanto para o $1 / 4 \mathrm{MS}$ quanto para o $1 / 2 \mathrm{MS}$, o uso de $15 \mathrm{~g} / \mathrm{L}$ de sacarose possibilitou maior número de raízes. Já, com o meio MS, a concentração de $30 \mathrm{~g} / \mathrm{L}$ de sacarose causou aumento desse número, comparado com o das outras concentrações. Dados semelhantes foram observados por Calvete et al. (2002) no cultivo de morangueiro.

Com 15 g/L e com $30 \mathrm{~g} / \mathrm{L}$ de sacarose, o meio 1/4MS possibilitou maior comprimento de raízes. A utilização de $15 \mathrm{~g} / \mathrm{L}$ de sacarose proporcionou maior formação de tecido radicular nos meios 1/4MS e 1/2MS. O uso de $15 \mathrm{~g} /$ $\mathrm{L}$ ou de $30 \mathrm{~g} / \mathrm{L}$ de sacarose, com o MS completo, não resultou em alteração no comprimento das raízes. Os dados obtidos mostram que esse carboidrato é essencial para o enraizamento in vitro de gemas axilares de atroveran.

É possível observar que a matéria seca de raiz (Tabela 3), produzida na concentração de sacarose de $15 \mathrm{~g} / \mathrm{L}$, foi maior com os meios $1 / 4 \mathrm{MS}$ e $1 / 2 \mathrm{MS}$. O $1 / 4 \mathrm{MS}$ apresentou efeito positivo com o uso de $30 \mathrm{~g} / \mathrm{L}$ de sacarose. Com o meio $1 / 4 \mathrm{MS}$, o uso de $15 \mathrm{~g} / \mathrm{L}$ de sacarose causou um aumento da matéria seca, tendo o mesmo efeito sido observado com o $1 / 2 \mathrm{MS}$. Com o MS completo, a concentração de $30 \mathrm{~g} / \mathrm{L}$ de sacarose mostrou melhor efeito. Ribeiro et al. (2009), trabalhando com copo de leite (Zantedeschia aethiopica), obtiveram resultados positivos com concentrações elevadas de sacarose $51 \mathrm{~g} / \mathrm{L}$ a $57 \mathrm{~g} / \mathrm{L}$.

Tabela 2. Valores médios de número de brotações, comprimento da brotação, matéria seca de brotação (MSB) e número de raízes de Ocimum selloi, nas diferentes variações de sais do meio de cultura MS e nas diferentes concentrações de sacarose, aos 30 dias

\begin{tabular}{lcccc}
\hline Meio de cultura & $\mathbf{N}^{\mathbf{0}}$ de brotações & $\begin{array}{c}\text { Comprimento } \\
\text { da brotação }(\mathbf{c m})\end{array}$ & MSB (mg) & $\mathbf{N}^{\mathbf{o}}$ de raízes \\
\hline 1/4MS & $2,00 \mathrm{a}$ & $0,66 \mathrm{a}$ & $5,60 \mathrm{a}$ & $2,00 \mathrm{a}$ \\
$1 / 2 \mathrm{MS}$ & $2,00 \mathrm{a}$ & $0,67 \mathrm{a}$ & $7,50 \mathrm{a}$ & $2,00 \mathrm{a}$ \\
MS & $2,00 \mathrm{a}$ & $0,51 \mathrm{a}$ & $6,10 \mathrm{a}$ & $1,00 \mathrm{~b}$ \\
\hline Sacarose $(\mathbf{g} / \mathbf{L})$ & $\mathbf{N}^{\mathbf{0}}$ de brotações & Comprimento & MSB $(\mathbf{m g})$ & $\mathbf{N}^{\mathbf{o}}$ de raízes \\
\hline 0 & $1,00 \mathrm{~b}$ & $0,13 \mathrm{c}$ & $1,42 \mathrm{c}$ & $0,00 \mathrm{~b}$ \\
15 & $2,00 \mathrm{a}$ & $1,28 \mathrm{a}$ & $10,92 \mathrm{a}$ & $2,00 \mathrm{a}$ \\
30 & $2,00 \mathrm{a}$ & $0,43 \mathrm{~b}$ & $6,37 \mathrm{~b}$ & $2,00 \mathrm{a}$ \\
\hline
\end{tabular}

Médias seguidas da mesma letra na coluna pertencem ao mesmo grupo de acordo com o teste Scott-Knott, a 5\% de probabilidade. 


\section{Experimento 2: Efeito da concentração do meio de cultura na germinação de sementes $e$ crescimento in vitro da plântula}

Em relação à ocorrência da contaminação das sementes, foi observado um índice de infestação de 38\% de fungos, indicando que a eficiência do processo de assepsia precisa ser melhorada. As sementes apresentam ranhuras e, umedecidas, apresentam a formação de uma camada mucilaginosa, o que pode ter induzido esta maior contaminação (Costa et al., 2010).

O meio MS contém 14 sais na sua composição e é o mais concentrado, o que pode ter afetado a percentagem de germinação e o IVG das sementes de $O$. selloi, por causa da pressão osmótica, fato este observado nos resultados deste trabalho. A diminuição do potencial osmótico, promovida pela redução das concentrações de sacarose, proporcionou as maiores taxas de germinação $(84$ a $74 \%)$ sem levar em conta a concentração do meio de cultura (Tabela 4). No entanto, quando se observa a suplementação com sacarose dentro de cada concentração de sais, a percentagem de germinação diminuiu. Verifica-se que a concentração de sacarose é mais crítica do que a concentração do meio de cultura. No entanto, não se deve considerar apenas a suplementação com sacarose, tanto para a percentagem de germinação como para o IVG, mas, o desenvolvimento da plântula in vitro. Apenas a sacarose não é suficiente para a manutenção da plântula in vitro, o uso do carboidrato e dos sais mostra ser necessário para a suplementação do meio de cultura.

Em trabalho realizado por Reis et al. (2008), foi demonstrado que a concentração dos sais do meio MS e a percentagem de sacarose influenciaram significativamente a germinação de sementes de Melissa officinalis.

$\mathrm{O}$ vigor das sementes, avaliado pelo IVG, também apresentou comportamentos distintos, em função das concentrações de sacarose e do meio de cultura. O maior IVG foi observado na ausência da sacarose $(0,98$ 1,04). Com a diminuição do potencial osmótico, devido à ausência de sacarose, as sementes tiveram maior absorção de água, o que favoreceu a velocidade de germinação. No entanto, com o aumento das concentrações de sacarose ( 15 e $30 \mathrm{~g} / \mathrm{L}$ ) e do meio de cultura, o índice de velocidade de germinação diminuí à medida que aumenta a concentração do meio de cultura. Neste caso, o potencial osmótico aumentou e, consequetemente, o índice de velocidade da semente diminuiu (Tabela 4). O mesmo comportamento foi relatado por Reis et al.

Tabela 3. Valores médios do comprimento da brotação $(\mathrm{cm})$, da matéria seca da brotação $(\mathrm{mg})$, do número de raízes, do comprimento de raízes $(\mathrm{cm})$ e de matéria seca de raízes $(\mathrm{mg})$ de Ocimum selloi na interação do meio de cultura e da concentração de sacarose, aos 30 dias

\begin{tabular}{|c|c|c|c|}
\hline \multirow{2}{*}{ Meio de cultura } & \multicolumn{3}{|c|}{ Sacarose $(g / L)$} \\
\hline & $\mathbf{0}$ & 15 & 30 \\
\hline & \multicolumn{3}{|c|}{ Comprimento da brotação } \\
\hline $1 / 4 \mathrm{MS}$ & $0,10 \mathrm{c} \mathrm{A}$ & 2,80 a A & $0,80 \mathrm{~b} \mathrm{~B}$ \\
\hline $1 / 2 \mathrm{MS}$ & $0,10 \mathrm{c} \mathrm{A}$ & 2,44 a B & $0,46 \mathrm{~b} B$ \\
\hline \multirow[t]{2}{*}{ MS } & $0,10 \mathrm{c} \mathrm{A}$ & 1,80 a $\mathrm{C}$ & $1,04 \mathrm{~b} \mathrm{~A}$ \\
\hline & \multicolumn{3}{|c|}{ Matéria seca da brotação } \\
\hline $1 / 4 \mathrm{MS}$ & $0,14 \mathrm{c} \mathrm{A}$ & 5,12 a $B$ & $3,22 \mathrm{~b} \mathrm{~B}$ \\
\hline $1 / 2 \mathrm{MS}$ & $0,10 \mathrm{c} \mathrm{A}$ & 6,62 a $A$ & $3,08 \mathrm{~b} \mathrm{~B}$ \\
\hline \multirow[t]{2}{*}{ MS } & $0,08 \mathrm{~b} \mathrm{~A}$ & 6,70 a $\mathrm{A}$ & 7,72 a A \\
\hline & \multicolumn{3}{|c|}{ Número de raízes } \\
\hline $1 / 4 \mathrm{MS}$ & $0,00 \mathrm{c} \mathrm{A}$ & 5 a A & $3 \mathrm{~b} \mathrm{~B}$ \\
\hline $1 / 2 \mathrm{MS}$ & $0,00 \mathrm{c} \mathrm{A}$ & 5 a A & $3 \mathrm{~b} \mathrm{~B}$ \\
\hline \multirow[t]{2}{*}{ MS } & $0,00 \mathrm{c} \mathrm{A}$ & $2 \mathrm{~b} \mathrm{~B}$ & $4 \mathrm{a} \mathrm{A}$ \\
\hline & \multicolumn{3}{|c|}{ Comprimento de raízes } \\
\hline $1 / 4 \mathrm{MS}$ & $0,00 \mathrm{c} \mathrm{A}$ & 2,02 a A & $1,26 \mathrm{~b} \mathrm{~A}$ \\
\hline $1 / 2 \mathrm{MS}$ & $0,00 \mathrm{c} \mathrm{A}$ & 1,40 a B & $0,72 \mathrm{~b} \mathrm{~B}$ \\
\hline \multirow[t]{2}{*}{ MS } & $0,00 \mathrm{~b} \mathrm{~A}$ & 0,64 a C & 0,68 a B \\
\hline & \multicolumn{3}{|c|}{ Matéria seca de raízes } \\
\hline $1 / 4 \mathbf{M S}$ & $0,00 \mathrm{c} \mathrm{A}$ & 0,92 a $\mathrm{A}$ & $0,72 \mathrm{~b} \mathrm{~A}$ \\
\hline $1 / 2 \mathrm{MS}$ & $0,00 \mathrm{c} \mathrm{A}$ & 0,74 a A & $0,28 \mathrm{~b} \mathrm{~B}$ \\
\hline MS & $0,00 \mathrm{~b} \mathrm{~A}$ & $0,06 \mathrm{~b} \mathrm{~B}$ & 0,38 a B \\
\hline
\end{tabular}

Médias seguidas da mesma letra, minúsculas na linha e maiúsculas na coluna, pertencem ao mesmo grupo de acordo com o teste Scott-Knott, a 5\% de probabilidade.

Rev. Ceres, Viçosa, v. 62, n.2, p. 215-223, mar-abr, 2015 
(2008), que observaram maior IVG no tratamento constituído do meio $1 / 4 \mathrm{MS}$, seguido do $1 / 2 \mathrm{MS}$.

No meio de cultura sem suplementação de sacarose, a plântula apresentou tendência de maior crescimento nas menores concentrações do meio de cultura, $1 / 4 \mathrm{MS}$, $1 / 2 \mathrm{MS}$ e, depois, MS completo. No meio apenas suplementado com sacarose, houve menor desenvolvimento da plântula (Tabela 4). Nos outros meios, suplementados com 15 e $30 \mathrm{~g} / \mathrm{L}$ de sacarose, a tendência foi a mesma. Observa-se que a presença do carboidrato mostrou ser necessária para a manutenção da plântula in vitro por um período mais longo.

A baixa concentração de sais e de sacarose no meio favorece a germinação da semente, pois proporciona menor pressão osmótica que a de um meio rico em nutrientes, favorecendo assim a absorção de água pela semente e, consequentemente, sua germinação.

Os dados mostram que a ausência de sacarose proporcionou resultados positivos sobre a altura da plântula, no período de 30 dias. Hua et al. (2010) observaram que o meio constituído de 1/4MS, com $15 \mathrm{~g} / \mathrm{L}$ de sacarose, foi melhor para germinação de esporo de samambaia; no entanto, o meio MS com $30 \mathrm{~g} / \mathrm{L}$ foi mais eficiente para o crescimento adicional.

Houve efeito da interação entre meio de cultura e concentração de sacarose sobre o número de raízes (Tabela 4). Na ausência de sacarose no meio MS e suas diluições houve menor número de raiz em relação ao controle. Com a utilização de $30 \mathrm{~g} / \mathrm{L}$ de sacarose, o maior número de raízes foi observado no meio $1 / 4 \mathrm{MS}$.
Houve efeito isolado do meio e da concentração de sacarose sobre a variável matéria fresca e seca de parte aérea e de raiz. Para a matéria fresca e seca da parte aérea, na ausência de MS, obteve-se menor ganho de massa. Os demais tratamentos não se diferenciaram entre si. Mesmo não havendo diferença entre esses tratamentos, recomenda-se o uso do $1 / 4 \mathrm{MS}$, tanto pela economia de material quanto pelo tempo de manutenção da plântula in vitro. Já, para a matéria fresca e seca de raízes, a ausência de sais do meio MS possibilitou maior formação de raízes, sendo este o tratamento que apresentou maior valor (Tabela 5). É provável que a falta de nutrientes tenha estimulado uma maior produção de tecido radicular.

Para o crescimento das matérias frescas de parte aérea e de raízes, a concentração de $30 \mathrm{~g} / \mathrm{L}$ de sacarose foi a que resultou em menor ganho de peso. As concentrações de 0 e $15 \mathrm{~g} / \mathrm{L}$ resultaram em valores similares e maiores de incremento de massa nas plântulas. Com relação às matérias secas da parte aérea e de raízes, a maior massa foi observado no tratamento que utilizou $15 \mathrm{~g} /$ L de sacarose (Tabela 5).

\section{Experimento 3: Efeito do tipo de substrato na aclimatização da plântula}

Não houve influência dos tratamentos sobre a taxa de sobrevivência das plântulas; no entanto, o crescimento e desenvolvimento foram altamente afetados pelo substrato utilizado (Tabela 6).

Para comprimento da planta, matéria seca da parte aérea, comprimento da raiz e matéria seca da raiz, o

Tabela 4. Valores médios da percentagem de germinação $(\% \mathrm{G})$ e índice de velocidade de germinação (IVG) na interação da variação de sais do meio MS e da concentração de sacarose, aos 30 dias

\begin{tabular}{|c|c|c|c|c|c|c|}
\hline \multirow{3}{*}{ MS } & \multicolumn{6}{|c|}{ Sacarose $(g / L)$} \\
\hline & \multicolumn{2}{|c|}{$\mathbf{0}$} & \multicolumn{2}{|c|}{15} & \multicolumn{2}{|c|}{30} \\
\hline & $\% \mathrm{G}$ & IVG & $\% \mathrm{G}$ & IVG & $\% \mathbf{G}$ & IVG \\
\hline $0 \mathrm{MS}$ & 76 a A & 1,04 a A & 78 a A & 1,02 a A & 63 a A & $0,80 \mathrm{~b} \mathrm{~A}$ \\
\hline $1 / 4 \mathrm{MS}$ & 75 a A & 1,03 a A & $52 \mathrm{~b} \mathrm{~B}$ & $0,60 \mathrm{~b} \mathrm{~B}$ & $54 \mathrm{~b} \mathrm{~A}$ & $0,60 \mathrm{~b} \mathrm{~B}$ \\
\hline $1 / 2 \mathrm{MS}$ & 74 a A & $0,80 \mathrm{a} \mathrm{A}$ & $54 \mathrm{~b} \mathrm{~B}$ & 0,71 a B & $53 \mathrm{~b} \mathrm{~A}$ & $0,50 \mathrm{~b} \mathrm{~B}$ \\
\hline \multirow[t]{2}{*}{ MS } & 84 a A & 0,98 a A & $34 \mathrm{~b} \mathrm{~B}$ & $0,41 \mathrm{~b} \mathrm{C}$ & $53 \mathrm{~b} \mathrm{~A}$ & $0,40 \mathrm{~b} \mathrm{~B}$ \\
\hline & \multicolumn{6}{|c|}{ Comprimento da parte aérea } \\
\hline $0 \mathrm{MS}$ & 0,43 a $\mathrm{B}$ & 0,38 a B & 0,39 a $\mathrm{A}$ & & & \\
\hline $1 / 4 \mathrm{MS}$ & 1,34 a A & $1,04 \mathrm{~b} \mathrm{~A}$ & 0,69 c A & & & \\
\hline $1 / 2 \mathrm{MS}$ & 1,14 a A & 1,01 a A & $0,57 \mathrm{~b} \mathrm{~A}$ & & & \\
\hline \multirow[t]{2}{*}{ MS } & 1,12 a A & $0,64 \mathrm{~b} \mathrm{~B}$ & $0,49 \mathrm{~b} \mathrm{~A}$ & & & \\
\hline & \multicolumn{6}{|c|}{ Número de raízes } \\
\hline $0 \mathrm{MS}$ & 7 a A & $4 \mathrm{~b} \mathrm{~A}$ & $3 \mathrm{~b} \mathrm{~B}$ & & & \\
\hline $1 / 4 \mathrm{MS}$ & 5 a B & 5 a A & 6 a A & & & \\
\hline $1 / 2 \mathrm{MS}$ & 5 a B & 6 a A & $3 \mathrm{~b} \mathrm{~B}$ & & & \\
\hline MS & 4 a B & $4 \mathrm{a} \mathrm{A}$ & 2 a B & & & \\
\hline
\end{tabular}

Médias seguidas da mesma letra, maiúscula na coluna e minúscula na linha, pertencem ao mesmo grupo de acordo com o teste Scott-Knott, a 5\% de probabilidade. 
Tabela 5. Valores médios, matéria fresca da parte aérea (BFPA), matéria seca da parte aérea (BSPA), matéria fresca de raiz (BFR), matéria seca de raiz (BSR), em diferentes variações de sais do meio MS e diferentes concentrações de sacarose, aos 30 dias

\begin{tabular}{lcccc}
\hline MS & BFPA $(\mathbf{m g})$ & BSPA $(\mathbf{m g})$ & BFR (mg) & BSR (mg) \\
\hline 0 & $8,0 \mathrm{~b}$ & $1,7 \mathrm{~b}$ & $6,0 \mathrm{a}$ & $0,9 \mathrm{a}$ \\
$1 / 4 \mathrm{MS}$ & $25,0 \mathrm{a}$ & $3,2 \mathrm{a}$ & $3,0 \mathrm{~b}$ & $0,6 \mathrm{~b}$ \\
$1 / 2 \mathrm{MS}$ & $26,0 \mathrm{a}$ & $3,1 \mathrm{a}$ & $3,0 \mathrm{~b}$ & $0,6 \mathrm{~b}$ \\
MS & $23,0 \mathrm{a}$ & $2,9 \mathrm{a}$ & $2,0 \mathrm{c}$ & $0,4 \mathrm{c}$ \\
\hline Sacarose (g/L) & BFPA (mg) & BSPA (mg) & BFR (mg) & BSR (mg) \\
\hline 0 & $25,0 \mathrm{a}$ & $2,5 \mathrm{~b}$ & $3,5 \mathrm{a}$ & $0,5 \mathrm{~b}$ \\
15 & $22,0 \mathrm{a}$ & $3,2 \mathrm{a}$ & $3,8 \mathrm{a}$ & $0,8 \mathrm{a}$ \\
30 & $15,0 \mathrm{~b}$ & $2,5 \mathrm{~b}$ & $2,8 \mathrm{~b}$ & $0,6 \mathrm{~b}$ \\
\hline
\end{tabular}

Médias seguidas da mesma letra na coluna pertencem ao mesmo grupo de acordo com o teste Scott-Knott, a 5\% de probabilidade.

Tabela 6. Valores médios da altura, número de entrenós ( $\left.\mathrm{N}^{\circ} \mathrm{E}\right)$, matéria seca da parte aérea (MSPA), percentagem de sobrevivência (\% S), comprimento da maior raiz (CMR) e matéria seca do sistema radicular (MSSR) de plântulas aclimatizadas de Ocimum selloi, aos 45 dias, em diferentes substratos

\begin{tabular}{|c|c|c|c|c|c|c|}
\hline Substrato & Comprimento $(\mathrm{cm})$ & $\mathbf{N}^{0} \mathbf{E}$ & $\operatorname{MSPA}(\mathbf{m g})$ & $\% \mathrm{~S}$ & $\operatorname{CMR}(\mathbf{c m})$ & MSSR (mg) \\
\hline Areia & $4,42 \mathrm{c}$ & $4,00 \mathrm{~b}$ & $27,00 \mathrm{c}$ & $100 \mathrm{a}$ & $10,37 \mathrm{~b}$ & $6,02 \mathrm{c}$ \\
\hline Plantmax $^{\circledR}$ & $8,90 \mathrm{a}$ & $7,00 \mathrm{a}$ & $226,28 \mathrm{a}$ & $95 \mathrm{a}$ & $19,25 \mathrm{a}$ & $95,18 \mathrm{a}$ \\
\hline Solo & $6,45 \mathrm{~b}$ & $5,00 \mathrm{~b}$ & $44,92 \mathrm{~b}$ & $100 \mathrm{a}$ & $13,52 \mathrm{~b}$ & $19,76 b$ \\
\hline Solo + Esterco bovino & $5,43 \mathrm{~b}$ & $5,00 \mathrm{~b}$ & $44,72 b$ & $95 \mathrm{a}$ & $11,47 \mathrm{~b}$ & $19,70 \mathrm{~b}$ \\
\hline
\end{tabular}

Médias seguidas da mesma letra na coluna pertencem ao mesmo grupo de acordo com o teste Scott-Knott, a 5\% de probabilidade.

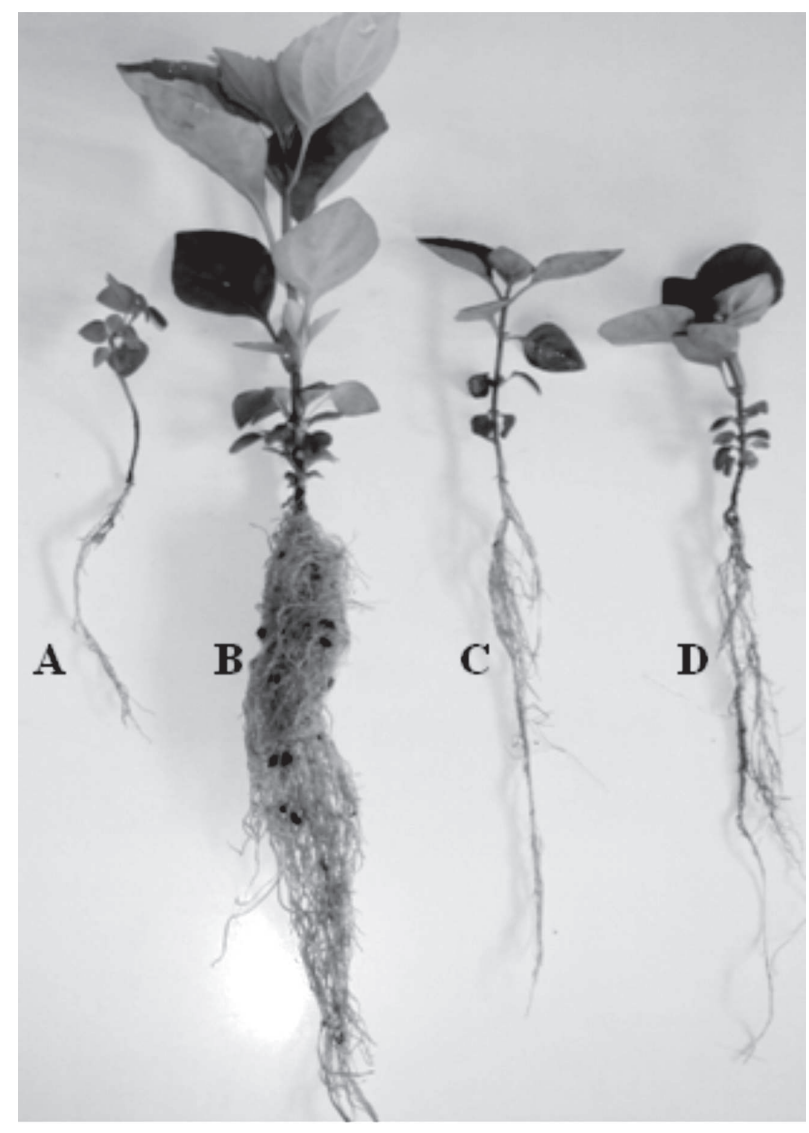

Figura 1. Parte aérea e sistema radicular de plantas de Ocimum selloi aclimatizadas em diferentes substratos, aos 45 dias. A) Areia. B) Substrato comercial. C) Solo. D) Solo + Esterco bovino (2:1). melhor substrato foi o comercial (Tabela 6). Por suas características físicas e químicas, o substrato comercial possibilitou melhor desenvolvimento da parte aérea e do sistema radicular da planta. Como a plântula é pequena e frágil, é essencial, para o seu desenvolvimento e crescimento, um incremento nutricional nos estádios iniciais. A areia, por ser um substrato com poucos nutrientes, não propiciou crescimento das raízes, mesmo tendo uma boa relação ar-água. Para Hartmann \& Kester (2002), o substrato adequado deve ser inerte, poroso, com boa drenagem e capaz de manter a aeração e a umidade, permitindo o desenvolvimento do sistema radicular.

A escolha do substrato poderia ser influenciada apenas pelo menor preço e disponibilidade, como é o caso da areia, facilmente encontrada e de menor custo para o produtor, porém, quando se analisa o desenvolvimento dessas plântulas, de acordo com os substratos utilizados, observa-se que um substrato mais rico nutricionalmente proporciona plântulas maiores, com condições de atingirem o estádio de mudas (Figura 1).

\section{CONCLUSÕES}

O uso de sacarose foi essencial para o estabelecimento e o crescimento de segmentos nodais de $O$. sello $i$ in vitro.

A redução da concentração dos sais do meio básico MS favorece o estabelecimento e o crescimento dos segmentos nodais de $O$. selloi in vitro. 
A diminuição do potencial osmótico, ou seja, a ausência de sacarose e de sais induziu uma maior percentagem de germinação e maior valor do índice de velocidade de germinação.

Substratos comerciais são mais indicados para a aclimatização de plântulas de $O$. selloi provenientes de cultivo in vitro.

\section{AGRADECIMENTOS}

À CAPES, pela concessão de bolsa de estudos, ao CNPq e à FAPEMIG, pela bolsa de produtividade, bolsa de apoio técnico e suporte financeiro.

\section{REFERÊNCIAS}

Bevilacqua CB, Reiniger LRS, Golle DP \& Rosa FC (2011) Desinfestação superficial, germinação e regeneração in vitro a partir de sementes de calêndula. Ciência Rural, 41:761-766.

Brasil (1992) Ministério da Agricultura e Reforma Agrária. Regras para análise de sementes. Brasília, SNDA. 365p.

Calvete EO, Kämpf AN \& Daudt R (2000) Efeito do substrato na aclimatização ex vitro de morangueiro cv. Campinas, Fragaria $x$ ananassa Duch. In: Kämpf NA \& Fermino MH (Eds.) Substratos para plantas: a base da produção vegetal em recipientes. Porto Alegre, Editora Gênesis. p.257-264.

Calvete EO, Azevedo M, Bordignon MH \& Suzin M (2002) Análises anatômicas e da biomassa em plantas de morangueiro cultivadas in vitro e ex vitro. Horticultura Brasileira, 20:649-653.

Costa LCB, Pinto JEBP, Bertolucci SKV \& Guimarães RM (2010) Qualidade fisiológica de sementes de Ocimum selloi Benth sob condições de luz, temperatura e tempo de armazenamento. Ciência e Agrotecnologia, 34:675-680.

Ferreira DF (2007) SISVAR: sistema de análise de variância. Versão 5.0. Lavras, Departamento de Ciências Exatas.

Ferreira AG \& Rosa SGT (2009) Germinação de sementes de sete espécies medicinais nativas do sul do Brasil. Revista Brasileira de Plantas Medicinais, 11:230-235.

Fráguas CB, Villa F, Souza AV, Pasqual M \& Dutra LF (2003) Crescimento in vitro de plântulas de orquídeas oriundas da hibridação entre Cattleya labiata e Laelia itambana. Revista Ceres, 50:719-726.

George EF, Hall MA \& Klerk GS (2008) Plant propagation by tissue culture: the background. $3^{\mathrm{a}}$ ed. Dordrecht, Springer. 501p.

Hartmann HT \& Kester DE (2002) Plant propagation: principles e practices. $7^{\mathrm{a}}$ ed. New Jersey, Prentice Hall. 880p.

Hua W, Xiu-Qun L, Hua J \& Long-Qing C (2010) Effects of light, macronutrients, and sucrose on germination and development of the endangered fern Adiantum reniforme var. sinense (Adiantaceae). Scientia Horticulturae, 125:417-421.

Maguire JD (1962) Speed of germination-aid in selection and evaluation for seedling emergence and vigor. Crop Science, 2:176-177.

Moraes CF, Suzin M, Nienow AA, Grando MF, Mantovani N, Calvete EO \& Donida BT (2010) Germinação in vitro de sementes de alcachofra. Horticultura Brasileira, 28:64-69.

Murashige T \& Skoog F (1962) A revised medium for rapid growth and bioassays with tobacco tissue cultures. Physiologia Plantarum, 15:473-497.

Murch SJ, Liu C, Romero RM \& Saxena PK (2004) In vitro culture and temporary immersion bioreactor production of Crescentia cujete. Plant Cell, Tissue and Organ Culture, 78:63-68.
Pessoa CC, Silva ALL da, Franco ETH \& Bisognin DA (2004) Propagação in vitro de Nephrolepis exaltata (L.) Schott. Caderno de Pesquisa Série Biologia, 16:43-49.

Reis ES, Pinto JEBP, Rosado LDS \& Corrêa RM (2008) Influência do meio de cultura na germinação de sementes in vitro e taxa de multiplicação de Melissa officinalis L. Revista Ceres, 55:160-167.

Ribeiro MNO, Pasqual M, Villa F \& Cavallari L da L (2009) Desenvolvimento in vitro de copo-de-leite: efeito das concentrações de sacarose e de ácido giberélico. Ciências Agrárias, 30:575-580.

Roy AR, Patel RS, Patel VV, Sajeev S \& Deka BC (2011) Asymbiotic seed germination, mass propagation and seedling development of Vanda coerulea Griff ex.Lindl. (Blue Vanda): An in vitro protocol for an endangered orchid. Scientia Horticulturae, 128:325-331.

Silva CG, Debiasi C \& Pescador R (2007) Enraizamento in vitro e aclimatização de mudas micropropagadas de Aloe vera $\mathrm{L}$. Revista Brasileira de Plantas Medicinais, 9:29-35.

Sun Y, Zhang D \& Smagula J (2010) Micropropagation of Ilex glabra (L.). HortScience, 45:805-808.

Vieira RF \& Simon JE (2000) Chemical characterization of basil (Ocimum spp.) found in the markets and used in traditional medicine in Brazil. Economic Botany, 54:207-216.

Villa F, Araújo AG de, Pio LAS \& Paqual M (2005) Multiplicação in vitro da amoreira-preta 'Ébano' em diferentes concentrações de meio MS e BAP. Ciência e Agrotecnologia, 29:582-589. 


\section{NOTA DE ESCLARECIMENTO}

A Comissão Editorial da Revista Ceres, através deste documento, vem a público esclarecer que a CAPES é patrocinadora dessa revista e desculpar-se por não haver nas edições 1, 2, 3, 4 e 5 de 2014 o logotipo dessa agência de fomento cujo patrocínio é essencial para a qualidade de nossas publicações.

Comissão Editorial da Revista Ceres 